\title{
Weathering of Antibacterial Melt-Spun Polyfilaments Modified by Pine Rosin
}

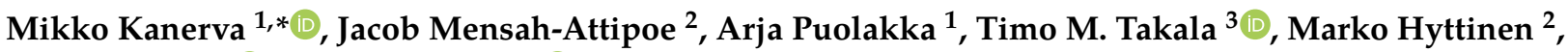 \\ Rama Layek $^{1,4}{ }^{\mathbb{D}}$, Sarianna Palola ${ }^{1} \mathbb{D}$, Vladimir Yudin ${ }^{5}$, Pertti Pasanen ${ }^{2}$ and Per Saris ${ }^{3}$ \\ 1 Faculty of Engineering and Natural Sciences, Tampere University, FI-33014 Tampere, Finland; \\ ao.puolakka@gmail.com (A.P.); rama.layek@lut.fi (R.L.); sarianna.palola@tuni.fi (S.P.) \\ 2 Department of Environmental and Biological Sciences, University of Eastern Finland, P.O. Box 1627, \\ FI-70211 Kuopio, Finland; jacob.mensah-attipoe@uef.fi (J.M.-A.); marko.hyttinen@uef.fi (M.H.); \\ pertti.pasanen@uef.fi (P.P.) \\ 3 Department of Microbiology, Helsinki University, P.O. Box 56, FI-00014 Helsinki, Finland; \\ timo.takala@helsinki.fi (T.M.T.); per.saris@helsinki.fi (P.S.) \\ 4 Department of Separation Science, School of Engineering Science, LUT University, Mukkulankatu 19, \\ FI-15210 Lahti, Finland \\ 5 Institute of Macromolecular Compounds, Russian Academy of Sciences, 31 Bolshoy pr. VO, \\ 199004 Saint-Petersburg, Russia; yudinve@gmail.com \\ * Correspondence: Mikko.kanerva@tuni.fi; Tel.: +358-40-718-8819
}

Citation: Kanerva, M.;

Mensah-Attipoe, J.; Puolakka, A.; Takala, T.M.; Hyttinen, M.; Layek, R.; Palola, S.; Yudin, V.; Pasanen, P.; Saris, P. Weathering of Antibacterial Melt-Spun Polyfilaments Modified by Pine Rosin. Molecules 2021, 26, 876. https://doi.org/10.3390/ molecules 26040876

Academic Editors: Bruce P. Lee, Bo Liu and Sylvain Caillol

Received: 16 November 2020

Accepted: 3 February 2021

Published: 7 February 2021

Publisher's Note: MDPI stays neutral with regard to jurisdictional clai$\mathrm{ms}$ in published maps and institutional affiliations.

Copyright: (C) 2021 by the authors. Licensee MDPI, Basel, Switzerland. This article is an open access article distributed under the terms and conditions of the Creative Commons Attribution (CC BY) license (https:// creativecommons.org/licenses/by/ $4.0 /)$.

\begin{abstract}
For many antibacterial polymer fibres, especially for those with natural functional additives, the antibacterial response might not last over time. Moreover, the mechanical performance of polymeric fibres degrades significantly during the intended operation, such as usage in textile and industrial filter applications. The degradation process and overall ageing can lead to emitted volatile organic compounds (VOCs). This work focused on the usage of pine rosin as natural antibacterial chemical and analysed the weathering of melt-spun polyethylene (PE) and poly lactic acid (PLA) polyfilaments. A selected copolymer surfactant, as an additional chemical, was studied to better integrate rosin with the molecular structure of the plastics. The results reveal that a high $20 \mathrm{w}-\%$ of rosin content can be obtained by surfactant addition in non-oriented PE and PLA melt-spun polyfilaments. According to the VOC analysis, interestingly, the total emissions from the melt-spun PE and PLA fibres were lower for rosin-modified (10 w-\%) fibres and when analysed below $60{ }^{\circ} \mathrm{C}$. The PE fibres of the polyfilaments were found to be clearly more durable in terms of the entire weathering study, i.e., five weeks of ultraviolet radiation, thermal ageing and standard washing. The antibacterial response against Gram-positive Staphylococcus aureus by the rosin-containing fibres was determined to be at the same level (decrease of 3-5 logs $\mathrm{cfu} / \mathrm{mL}$ ) as when using $1.0 \mathrm{w}-\%$ of commercial silver-containing antimicrobial. For the PE polyfilaments with rosin $(10 \mathrm{w}-\%)$, full killing response (decrease of 3-5 logs cfu/mL) remained after four weeks of accelerated ageing at $60{ }^{\circ} \mathrm{C}$.
\end{abstract}

Keywords: durability; antibacterial response; pine rosin; volatile organic compounds

\section{Introduction}

Sustainability will be a crucial property in the development of new materials. Due to the necessities of circular economy and sustainable balance between us and our alive surroundings, large amounts of bio-based polymers and polymers with natural, degradable components have been introduced in the literature during the recent years [1-3]. These materials are not of practical use, if the intermediate forms, like fibres and polyfilaments, can not reach the performance requirements or if the safety towards living organisms is unacceptable in the operational environment.

Fibres, having two of the three dimensions small, are prone to affect their environment because of the high surface to volume ratio. Medicinal and other fibres with an antimicrobial response are developed to protect against virus and bacterial strains that are hazard to a 
human [4-6]. Silver is typical additive to make antimicrobial fibres [7-9]. Silver itself is considered an expensive and toxic element and related modifications for antimicrobial compounds, i.e., polymer systems including nano particles and surface functionalization [10], rarely improve this character [11,12]. Natural components could be a solution for healthier, profitable and sustainable additives in functional antimicrobial fibres.

In spite of the development work and scientific characterization of numerous reported antimicrobial fibres and polymers, the detailed understanding of the long-term durability and related degradation is not well understood for functional polymer fibres with natural additives. Typically, the durability of the antimicrobial response is much less than the mechanical durability of the basis polymer structure $[13,14]$. The durability at elevated temperatures is especially important because the degradation products might get emitted in a gaseous form during the use of a textile product; some degradation can occur already during processing after the fibre cool-down [15]. The durability of polymer fibres with natural components at elevated temperatures and/or moist environment is typically lower compared to synthetic rivals due to the (natural) additives [16].

Pine rosin has been researched in various antimicrobial polymer systems for a few decades and its antibacterial response has led to many applications related to medical wound healing, for instance $[17,18]$. The chemical content of rosin (resin) depends naturally on the exact tree species, the part of tree being used and the extraction process [19-21]. Rosin alone or its derivatives as well rosin as additive in various polymeric systems have been proven antimicrobial against several Gram-positive and Gram-negative bacteria [22-24] and fungi [25-27]. Even when rosin is externally subject to living organisms, it can form low-molecular weight emissions (volatile organic compounds, VOCs) that could be defined as harmful in large quantities [28,29]. Moreover, the higher the temperature and longer the exposure time, the stronger the released emission and degradation of rosin are expected to be. However, in-depth studies about the mechanical durability, VOC emissions, along with antibacterial response in advanced polymer systems, such as melt-spun polyfilaments, have not been reported.

\section{Background}

Rosin in polymeric fibres and textiles has great potential to bring in multiple benefits for the final products. First, rosin-polymer polyfilaments and the formed textiles or filters have a strong antibacterial response. Second, rosin (or tall oil) itself is a by-product of the forest industry [30] — the use of rosin increases the sustainable efficiency of forest industry and rosin can be a cost-efficient additive for antimicrobial products. Third, rosin is a completely natural additive, thus, the higher the content of rosin in the final product, the higher is the bio content of the product. In the current literature, high rosin concentrations have been studied for several polymers: polyamide 6 (PA), polyethylene (PE), polypropylene, poly lactic acid (PLA) and a starch-based polymer compound [6]. The reported work focused on the polyfilament melt-spinning of these polymers and blends at $0 . .20 \mathrm{w}-\%$ concentration of rosin. The maximum rosin concentration was determined to be $\approx 10 \mathrm{w}-\%$ [6]. A high $(\approx 20 \mathrm{w}-\%)$ rosin dosage leads to disintegration and accumulation of rosin at the spinneret and subsequent unstable flow and fibre formation during polyfilament spinning; the melt viscosity of rosin and its low-molecular weight components are relatively low.

The reported problems at high rosin concentrations might have been due to the low compatibility and incomplete mixing of rosin within the polymer melt. For this, a surfactant chemical could be used to improve the melt compatibility. Typically, the surfactant's type is selected based on the surface functionality of the compounds to be mixed. Rosin is the mixture of a wide spectrum of compounds including phenolic compounds, waxes, a large variety of fatty acids as well as terpenoid, sterol and terpene (resin) acids. In turn, polyolefins do not have special functionality. Since ionic surfactant is typically preferred for an aqueous dispersion and solid particles [31,32], polymeric surfactant is presumed to be a suitable candidate for rosin-polymer blends. The improvements by the selected surfactant could be listed as enhanced spinning process and quasi-static mechanical properties 
(stiffness, ultimate strength, ductility). For the following research, a non-ionic copolymer surfactant was selected. The proper surfactant concentrations for dispersing plant-based natural materials have been reported to be $0.09 .0 .3 \mathrm{w}-\%$ (of dry weight) in the current literature [33]. In the following research, a concentration of $0.166 \mathrm{w}-\%$ (of the total dry weight, $1 \%$ of rosin weight) is selected to be used with the polymer-rosin blends.

In the work by Kanerva et al., the functionality, i.e., the antibacterial response against Gram-positive Staphylococcus aureus and Gram-negative Escherichia coli, was reported to be highly dependent on the type of polymer applied. The strongest reported response was achieved with rosin-containing polyfilaments with either PA, PE or PLA basis [6]. However, no comparison with any rival synthetic additive was made in terms of the antibacterial response. To understand the level of antibacterial response of the rosincontaining polyfilaments, compared to a synthetic commercial additive, a selected silvercontaining additive is studied in the following research. The concentration range (1-2 $\left.\mathrm{w}_{-} \mathrm{-} \%\right)$ of the silver-based additive is selected based on the existing literature $(2.0 \mathrm{w}-\%)$ [9]. An initial survey indicated similar performance for $1 \mathrm{w}-\%$ and $2 \mathrm{w}-\%$ additive concentrations. Therefore, the antibacterial response of the polyfilament series with the lower (1 w- $\%)$ dosage is reported as a realistic (economical) comparison with rosin.

The long-term durability of the antibacterial response was not reported in the work by Kanerva et al. [6]. For textile and filter applications, for example, fibres are exposed to ultraviolet (UV) radiation from the sun and they degrade in terms of mechanical properties. Various clothing and filter applications are possible for melt-spun polyfilaments. For standard washing programs, the highest temperatures can be detrimental to a polymeric product. Weathering, including thermal cycling, washing and ultraviolet (UV) irradiation, is considered for the PE and PLA polyfilaments with a rosin concentration of $10 \mathrm{w}-\%$ in the following research.

\section{Materials and Methods}

\subsection{Polymer Raw Materials and Fibre Melt-Spinning}

The polymer raw materials used for the compounding and fibre spinning in this work are given in Table 1. As-received granulate was dried before compounding. To achieve antibacterial response, pine gum rosin (acid value $167 \mathrm{mg} \mathrm{KOH} / \mathrm{g}$, softening point $74^{\circ} \mathrm{C}$ ) (Ro) by Forchem (Finland) was used as natural functional additive; the spinning performance of rosin in various melt-spun polyfilaments has been recently reported [6]. The characterization of the pine rosin grade used can be found in previous works [6,34]. All of the polymer blends of this study were compounded by using a model TSE 25 twin-screw extruder (Brabender, Germany). After extruding a string of the compounded polymer system, it was cut into 2-4 mm-size granulate particles by a mechanical crusher. The granulate per polymer was used to feed the polyfilament spinning apparatus. All of the polyfilaments in this study were melt-spun by using a polyfilament spinning system (Fourné Polymertechnik $\mathrm{GmbH}$, Germany) and more information about the spinning process can be found in a recent work [6]. No lubricant or fibre finish was used during the spinning process. The main processing parameters of the blends of this study are given in Table 2 . It should be noted that no orientation was applied for the polyfilaments of this study.

Table 1. Polymers for preparing antibacterial multifilament fibres.

\begin{tabular}{ccc}
\hline Polymer Basis & Grade & Provider \\
\hline High-density polyethylene (HDPE) & CG9620 & Borealis Polymers \\
Poly lactic acid & $2003 \mathrm{D}$ & Ingeo/NatureWorks \\
\hline
\end{tabular}

Due to the challenges followed by very high rosin concentrations, bio-reagent type copolymer surfactant (PF) F-127 by Pluronic, purchased from Sigma Aldrich (Merck KGaA, Germany, Darmstadt) was studied here. The surfactant-containing blends were prepared as follows: Firstly, $300 \mathrm{~g}$ of rosin was mixed with surfactant ( $1 \mathrm{w}-\mathrm{\%}$ of rosin dry weight) by 
manual grinding using a ceramic mortar pestle and, then, kept in an oven $\left(100{ }^{\circ} \mathrm{C}\right)$. Secondly, the mixture was cooled to room temperature and crushed well. This procedure was repeated three times to obtain surfactant-modified rosin. The surfactant-modified polymer blends (see Table 3) were obtained by melt-compounding of the mixture of surfactant and rosin with as-received polymer granulate.

Table 2. Processing parameters for melt-spinning of rosin-containing blends.

\begin{tabular}{cccc}
\hline Polymer & Rosin $\%(w / w)$ & Temperature $\left({ }^{\circ} \mathrm{C}\right)$ & Series Names \\
\hline PE & 0,10 & 160,180 & fPE-160, fPE10-160, \\
PLA & 0,10 & $160-180$ & fPE10-180 \\
\hline
\end{tabular}

Table 3. Processing parameters for melt-spinning of surfactant (PF) containing blends.

\begin{tabular}{cccc}
\hline Polymer & PF/Ro, Ro & Temperature $\left({ }^{\circ} \mathbf{C}\right)$ & Series Names \\
\hline PE & $0.01,20 \%(w / w)$ & 160 & fPE1PF \\
PLA & $0.01,20 \%(w / w)$ & 160 & fPLA1PF \\
\hline
\end{tabular}

Commercial 'synthetic' medical-purpose silver nanoparticles (Poviargol, Russia) were used to compound and melt-spin and analyse a comparative polyfilament series. The silvercontaining (Ag) compounds were prepared by mixing as-received polymer granulate with the Ag-additive (powder-like form). Then, the mixture was fed to a compounder in small quantities $(\approx 50 \mathrm{~g})$ with a masterbatch basis. The desired diluted blends were compounded immediately to have 1\% (and 2\% for an initial survey) Ag-additive concentrations per compound (see Table 4). The Ag-containing particles were characterized using scanning electron microscopy (SEM) by a device Zeiss ULTRAplus (Zeiss, Germany) and elemental analysis by an integrated sensor for X-ray energy dispersive spectroscopy (EDS) (INCA Energy 350 EDS analyser, INCAx-act detector, Oxford Instruments, Oxford, UK).

Table 4. Processing parameters for melt-spinning of silver additive (Ag) containing blends.

\begin{tabular}{cccc}
\hline Polymer & Ag $\%(w / w)$ & Temperature $\left({ }^{\circ} \mathrm{C}\right)$ & Series Names \\
\hline PE & 1 & 180 & fPE1Ag \\
PLA & 1 & 180 & fPLA1Ag \\
\hline
\end{tabular}

\subsection{Antibacterial Activity}

The antimicrobial activity of the various polymer systems was tested against indicator bacteria Staphylococcus aureus ATCC 12598. The indicator was cultured at $37{ }^{\circ} \mathrm{C}$ in lysogeny broth (LB), with $1.5 \%$ agar for solid media. Antibacterial tests with the material samples were carried out in Ringer's solution of $1 / 4$ strength (i.e., mixture of $\mathrm{NaCl}, \mathrm{KCl}, \mathrm{CaCl}_{2}$, $\mathrm{NaHCO}_{3}$ and distilled water). The sample fibres were collected so that a mass of $0.1-0.14 \mathrm{~g}$ was used per fibre series and, for granulate form, $0.5 \mathrm{~g}$. The indicator strain was first cultured overnight in LB broth. Colony forming units per $\mathrm{mL}$ of the $\mathrm{o} / \mathrm{n}$ culture was determined by serial dilutions in 1/4 strength Ringer's solution and plating onto LB agar. From the serial dilutions of $10^{3}-10^{4}, 1 \mathrm{~mL}$ (about $10^{5}-10^{7} \mathrm{cfu} / \mathrm{mL}$ ) was used for the antimicrobial test by mixing with the sample fibres inside 2-mL Eppendorf tubes. The mixtures were incubated for $24 \mathrm{~h}$ at a room temperature in a rotator (at $22 \mathrm{rpm}$ ). After incubation, the samples were serially diluted in $1 / 4$ strength Ringer's solution, and plated onto LB agar for determining the bacterial survival by colony counting. At least duplicates were analysed. In this study, the control and reference samples were polyamide 6 polyfilaments with zero and $10 \mathrm{w}-\%$ rosin, respectively (series names fPA and fPA10), from the polyfilament fibre batch with details of preparation reported in a recent work [6]. 


\subsection{Volatile Organic Compounds Analysis}

Volatile organic compounds (VOC) were analysed for the polymer fibres to understand the safety and stability at elevated temperatures. Two parallel sets of seven fibre samples (of which five reported here, fPE, fPE10, fPLA, fPLA10 and fPLA1Ag) were analysed. The polyfilament fibres $(\approx 1 \mathrm{~g})$ were wrapped around stainless steel cylinders (cylinders acetone-washed and dried, individual cylinder per fibre sample used) to form neat bundles of fibre. The bundles were removed from the cylinders prior to the analysis into the measurement chambers. For the analysis, the samples were placed in the chambers of M-CTE250 (M-CTE250, Markes Micro-chamber/Thermal Extractor, Markes International, UK); the chambers were acetone-washed and dried by heating in an oven at $180{ }^{\circ} \mathrm{C}$ for three hours. Before the analysis, each sample was weighed and analysed for emissions at three temperatures: $\left(25^{\circ} \mathrm{C}, 60^{\circ} \mathrm{C}\right.$ and $\left.105^{\circ} \mathrm{C}\right)$. The materials were heated with the M-CTE250. Before sampling, the materials were allowed to equilibrate at a set temperature for five minutes. The temperature of the MCTE250 chambers was ramped up from the lowest to the highest temperature per test. The chemicals emitted from the materials were collected into Tenax TA tubes at an average flow rate of $63 \mathrm{~mL} / \mathrm{min}$ for five minutes for two first temperatures $\left(25^{\circ} \mathrm{C}\right.$ and $\left.60{ }^{\circ} \mathrm{C}\right)$ and for one minute when sampling at $105^{\circ} \mathrm{C}$.

At the end of a sampling interval, the tubes were removed and capped with the brass storage caps and, thereafter, analysed with the GC-MS. The Tenax TA tubes were analysed by a gas chromatograph (7890, Agilent, US) equipped with a mass selective detector (5975C, Agilent, Santa Clara, CA, USA) after thermal desorption (TD) (Markes TD-100, Markes International, Llantrisant, UK). The oven program included: $38{ }^{\circ} \mathrm{C}$ for $4 \mathrm{~min}$ then $5^{\circ} \mathrm{C} / \mathrm{min}$ to $210^{\circ} \mathrm{C}$ for $0 \mathrm{~min}$ and finally $20^{\circ} \mathrm{C} / \mathrm{min}$ to $280^{\circ} \mathrm{C}$ for 6.5 minutes. The total run time for a sample was $48.4 \mathrm{~min}$. The transfer line temperature was $350{ }^{\circ} \mathrm{C}$ and it was directly connected to HP-5 silica capillary column $(60 \mathrm{~m} \times 250 \mu \mathrm{m} \times 0.25 \mu \mathrm{m})$. The resolved analytes were detected using an electron impact mass spectrometer (MS) (5975, Agilent Technologies, Santa Clara, CA, USA). The identification of the compounds was accomplished by the retention times, standard compounds and GC-MS data library. The MS was operated in the scan mode. The standard tubes were analysed similarly as the sample tubes. The total volatile organic compounds (TVOCs) values were defined as the integrated detector response value in toluene equivalents of compounds eluting between and including C6 to C16 as given in the standard ISO 16000-6:2004. The detailed (tabulated compounds) VOC data and chromatograms (total ion chromatograms) per sample material are included as Supplementary Material S1 and S2.

\subsection{Conditioning by UV Radiation}

Outdoor degradation of the fibres was simulated by subjecting the polyfilaments (loose fibre loops were formed) to UV-B radiation (UVA-340 lamps, Q-Lab, Westlake, OH, USA) with peak intensity of $340 \mathrm{~nm}$ and dose of $0.001 \mathrm{GJ} /\left(\mathrm{m}^{2} \mathrm{~h}\right)$ inside a laboratory UV-cabinet (test area $0.89 \mathrm{~m}^{2}$ ). The resistance against the radiation was analysed with a combination of tensile testing and conditioning in the UV-cabinet (temperature in the cabinet $30-31{ }^{\circ} \mathrm{C}$, total exposure time $0-504 \mathrm{~h}$ ). Single fibre samples were extracted for mechanical testing every seven days for tensile testing.

\subsection{Conditioning by Thermal Cycling}

Pure thermal effects where studied by a combination of tensile testing and thermal ageing in an oven. The fibres (loose loops were formed) were laid in a digitally controlled, air-circulating oven $\left(60^{\circ} \mathrm{C}\right)$. Single fibre samples were extracted from the loops every seven days for mechanical testing to understand the effects of elevated temperature.

\subsection{Conditioning by Standard Washing}

The durability against standard washing (e.g., related to anticipated textile/clothing applications) was analysed with a combination of tensile testing and standard washing cycles according to the standard SFS-EN ISO 6330. The standard washing machine (Wascator 
FOM71MP-Lab, Electrolux, Sweden) was used at a temperature of $70^{\circ} \mathrm{C}$, with $20 \mathrm{~g}$ of IECdetergent per wash, and, ten subsequent washing cycles were performed. Each polyfilament yarn was loosely fixed to form loops, inside the machine.

\subsection{Mechanical Testing of Fibres from Polyfilaments}

Mechanical properties, i.e., ultimate (peak) engineering stress and ultimate strain (at break) were measured by using a tensile fibre tester (Favigraph, Textechno, Germany). For calculating the stress values (peak force per cross-sectional area), fibre (filament) diameters were measured individually per test fibre; the individual fibre diameter was measured by using a visual light (VL) microscope. The test rate was $20 \mathrm{~mm} / \mathrm{min}$ and a pre-tension of $\approx 0.7 \mathrm{cN}$ was applied. By default, ten parallel fibre samples of a polyfilament were measured per blend series and average and standard deviations were reported.

\section{Results and Analysis}

\subsection{Performance of As-Spun Polyfilaments in the Room Conditions}

The antibacterial response of PE and PA-6 fibres with $10 \mathrm{w}-\%$ of rosin, against $S$. aureus bacteria, was recently reported to be approximately four logs (input $\approx 300,000$ ) during $24 \mathrm{~h}$ of mixing (Ringer's solution) at a room temperature [6]. The reported response of granulate (polymer prior spinning) was even higher, almost five logs (input over one million). For PLA and $10 \mathrm{w}-\%$ of rosin, the response was significant but clearly less, one log of decrease. In this study, the as-spun polyfilament fibres (PA-6 polymer basis) of the same batch (as in a work [6]) repeatedly created the same response $(\approx 4 \operatorname{logs})$ with the current bacterial input of over one million. It should be noted that the fibres without rosin do not have antibacterial response (within the experimental scatter). To compare the rosin-induced antibacterial response to that of the Ag-containing synthetic rival, the results are clear in Figure 1. Similarly to the fibre-granulate dependence in the previous work, the response of the Ag-containing granulate (prior to spinning) is higher than that of the melt-spun fibre form. This suggests that the silver-containing particles are not located on the melt-formed surface of fibre as much as inside the fibre bulk-contrary to the granulate that always includes the fracture surface (due to the crushing process) that exposes the inside of the polymer bulk to the bacteria. Alternatively, for rosin-containing fibres, it could indicate removal of part of rosin (vaporized emissions) from the polymer bulk during the melt-spinning. In general, the antibacterial response of the rosin-containing fibres (fPA10 series [6]) was at the same level than the response of the fibres (and granulate) with the $1 \mathrm{w}-\%$ concentration of Ag-additive.

SEM imaging indicated essentially spherical morphology for the silver-containing additive particles, shown in Figure 2. The EDS spectrum revealed approximately 58\%-content of silver. The particles have been treated by poly(vinylpyrrolidone) by the manufacturer to form compatible surfaces and stable dispersion with various polymer systems [9]. Here, poly(vinylpyrrolidone) was indicated by the oxygen (nitrogen) content in the spectrum (Figure $2 b$ ). The high silver content of the additive agrees with the good antibacterial response of the Ag-containing polyfilaments of this study. The efficacy of nano-sized silver and poly(vinylpyrrolidone) alone against $S$. aureus has been reported in the current literature [10].

The tensile mechanical properties of the melt-spun polyfilaments in the room conditions are summarized in Table 5. Based on the revealed properties and spinnability, the use of surfactant with blends of $20 \mathrm{w}-\%$ rosin led to stable spinning performance and acceptable mechanical strength. However, the ultimate strength was 7-40\% lower compared to pure PE fibres (spinning at $160^{\circ} \mathrm{C}$ and $180^{\circ} \mathrm{C}$ ) and $38 \%$ lower compared to fibres with $10 \mathrm{w}-\%$ rosin content. For the PLA systems, the surfactant modification-likewise for PE-allowed spinning at a $20 \mathrm{w}-\%$ rosin content but the determined ultimate strength of the fibres was essentially the same as for the PLA fibres with a $10 \mathrm{w}-\%$ rosin content. Additionally, the fibres spun with the surfactant dosage were brittle (low strain at break). In summary, the use of the selected surfactant did not essentially improve the mechanical performance of 
rosin-containing PE and PLA fibres in the room conditions. Therefore, the PF-series fibres were not studied further for long-term durability. For an application, where merely a high rosin content is important in the final product, the use of surfactant could be considered.

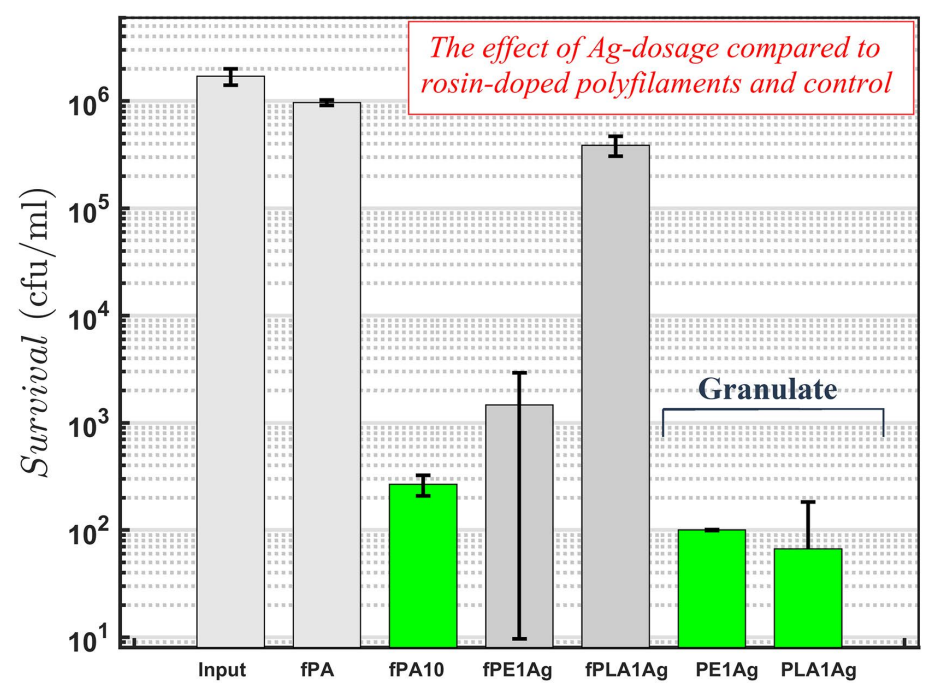

Figure 1. Antibacterial response of melt-spun polyfilmants against $S$. aureus in liquid (Ringer's solution, 1/4 strength) after $24 \mathrm{~h}$ mixing at room temperature: Ag-containing PE and PLA samples with $1 \mathrm{w}-\%$ of additive concentration in both fibrous (polyfilament) and granulate form (prior to meltspinning) are compared to polyamide-6 [6] control and reference samples (fPA, fPA10). The detection limit is $3 \times 10^{1} \mathrm{cfu} / \mathrm{mL}$.

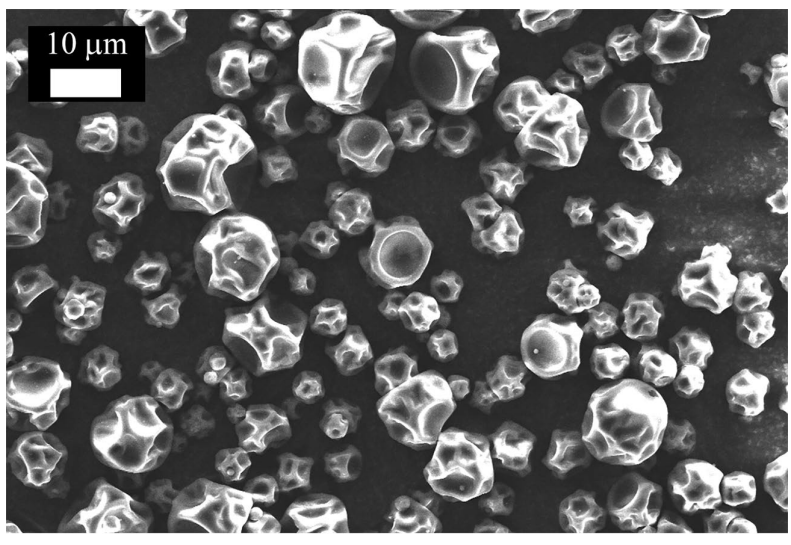

(a)

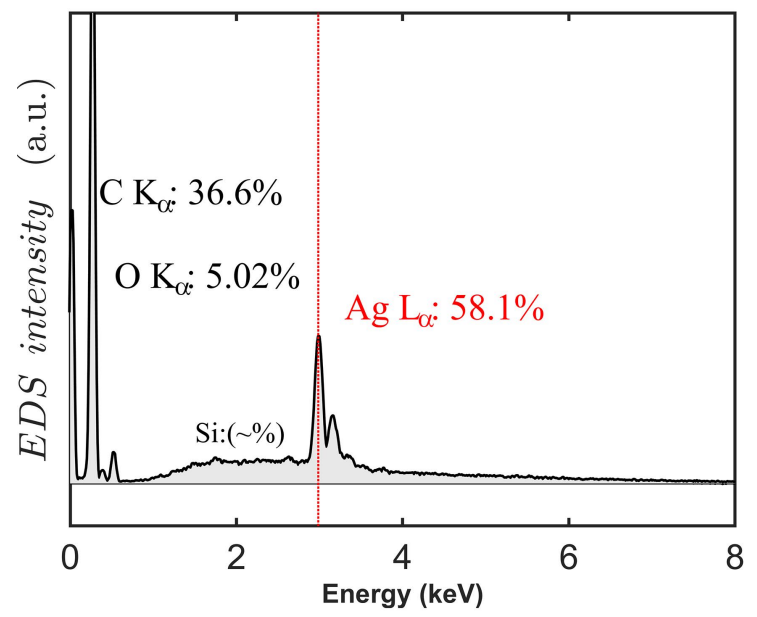

(b)

Figure 2. Characteristics of the Ag nanoparticles: (a) SEM imaging of particle size variation and particle morphology; (b) the EDS spectrum measured on Ag nanoparticles and the elemental distribution.

Table 5. Mechanical properties of fibres and the determined mechanical properties per additive concentration, respectively.

\begin{tabular}{|c|c|c|c|}
\hline Fibre Series & Additive(s) & Ultimate Strength (MPa), Respectively & Strain $(\delta L / L)$ at Break $(\%)$, Respectively \\
\hline fPE-160, from [6] & Ro $(0,10 \mathrm{w}-\% \mathrm{f})$ & $63 \pm 17,61 \pm 26$ & $1130 \pm 95,1528 \pm 210$ \\
\hline fPE-180, from [6] & $\operatorname{Ro}(0,10 \mathrm{w}-\%)$ & $41 \pm 20,19 \pm 11$ & $2076 \pm 242,1118 \pm 225$ \\
\hline fPE1PF & PF, Ro $(20 w-\%)$ & $38 \pm 16$ & $1234 \pm 491$ \\
\hline fPE1Ag & $\operatorname{Ag}(1 \mathrm{w}-\%)$ & $53 \pm 47$ & $1407 \pm 574$ \\
\hline fPLA, from [6] & Ro $(0,10 w-\%)$ & $153 \pm 47,49 \pm 5$ & $294 \pm 60,3 \pm 0$ \\
\hline fPLA1PF & PF, Ro $(20 w-\%)$ & $77 \pm 30$ & $4 \pm 1$ \\
\hline fPLA1Ag & $\operatorname{Ag}(1 \mathrm{w}-\%)$ & $146 \pm 47$ & $231 \pm 73$ \\
\hline
\end{tabular}


For the Ag-containing PE and PLA fibre series, compounds were successfully prepared and polyfilament fibres melt-spun. The powder-form Ag-additive dispersed well within the polymer blend based on visual observation. Similarly, the results with a similar performance as for PE and PLA fibres without the Ag-additive indicate good mixing during compounding. In detail, the fPE1Ag series PE fibres had 13-16\% lower strength compared to pure PE and $10 \mathrm{w}-\%$ of rosin containing fibres (spinning at $160{ }^{\circ} \mathrm{C}$ ). The fPLA1Ag series PLA fibres had only 5\% lower strength and $21 \%$ lower strain at break-the results suggested better compatibility of the Ag-additive with PLA than with the PE grade used. In summary, the Ag-additive at $1 \mathrm{w}-\%$ concentration resulted in appropriate melt-spun polyfilaments, and, it does represent a mechanically realistic synthetic reference for the research of antibacterial response of polyfilaments with rosin.

\subsection{Stability of Polyfilaments in Terms of Volatile Organic Compounds at Elevated Temperatures}

The melt-spun polyfilaments with PE and PLA basis were studied in terms of VOC to estimate the stability of the fibres at immediate elevated temperatures. The total volatile organic compounds (TVOCs) detected in the materials at $25{ }^{\circ} \mathrm{C}, 60{ }^{\circ} \mathrm{C}$ and $105{ }^{\circ} \mathrm{C}$ are presented in Table 6. It can be seen that PE fibres emit minor TVOCs already at the room temperature $\left(25^{\circ} \mathrm{C}\right)$. For PLA basis, the range of observed concentrations range from zero to a very low level through the measurement at the room temperature. Interestingly, for all the fibres, the rosin-containing fibres resulted in significantly (23-84\%) lower emitted organic compounds (TVOCs). This observation suggests that rosin could form a film or skin on the outer surface of the melt-spun polyfilaments that prevents the organic compounds being emitted from inside the bulk. When considering the results of antibacterial response (comparison between fibre and granulate), this is an opposite indication. Therefore, the lower TVOCs might indicate that rosin in general stabilizes the polymer-rosin blend (at low temperatures). This trend continued for PE and PE-rosin fibres at $60{ }^{\circ} \mathrm{C}$. On the contrary, the measurement of fPLA10 series resulted in 46\% higher TVOCs, although, the range of measured concentration during the measurement was broad (range $81 \%$ of the mean value).

Table 6. Average and range (deviation) of total volatile organic compound (TVOC) (ng/L/g) measured from the parallel polyfilament samples at different temperatures. Collection between 6.0 and $36.4 \mathrm{~min}$ (retention time) per sample and temperature. Chromatograms are given in the Supplementary Material S2.

\begin{tabular}{cccc}
\hline Fibre Series & Temperature $25^{\circ} \mathrm{C}$ & Temperature $60^{\circ} \mathbf{C}$ & Temperature 105 ${ }^{\circ} \mathbf{C}$ \\
\hline fPE & $381(255-308)$ & $8386(6252-10,520)$ & 160,092 \\
fPE10 & $113(113-114)$ & $6637(6434-6840)$ & 214,205 \\
fPLA & $40(39-41)$ & $766(532-1000)$ & $(200,338-228,071)$ \\
fPLA10 & $31(0-31)$ & $1120(691-1548)$ & $(18,531-20,233)$ \\
fPLA1Ag & $46(30-61)$ & $1132(442-1832)$ & $38,693,861-1,290,588)$ \\
\hline
\end{tabular}

The Ag-containing fibre series resulted in clearly higher (15-48\%) TVOCs compared to the pure and rosin-containing PLA fibres at $25^{\circ} \mathrm{C}$. At $60^{\circ} \mathrm{C}$, the TVOCs were on the same level as for the fPLA10 series and $48 \%$ higher than for pure PLA fibres.

At a temperature of $105^{\circ} \mathrm{C}$, the chemically rich chemistry of rosin begins to disintegrate. This is obvious by noting that the melting temperature of rosin is $\approx 70{ }^{\circ} \mathrm{C}[6]$. At $105{ }^{\circ} \mathrm{C}$, the rosin-containing fibres resulted in 33-470\% higher TVOCs compared to the reference fibres without rosin. The detailed (tabulated compounds) VOC reporting and chromatograms (total ion abundance as a function of retention time) per sample are included for readers as Supplementary Materials S1 and S2. For the fPE10 series, some propanoic acid (2-methyl-) was observed and it was not indicated for the fPE fibres without rosin. Propanoic acid is naturally occurring and inhibits some moulds and bacterial 
strains [35]. For the fPLA10 series, terpineol (p-menth-1-en-8-ol) was clearly observed-this substance is used as biocide chemical and, likewise propanoic acid, it is due to the rosin in the fibres [36]. For PLA with rosin (fPLA10 series), also propanoic acid was observed, expectedly. In addition, limonene and pinene (monoterpenes) were found and these terpene molecules are typical in plant essential oils as well as in pine rosin [25,28,37]. A minor limonene trace was also found for the fPLA10 series. For many of the fibres, in general, caryophyllene and 1,4-methanoazulene compounds were observed-yet as minor traces for the fibres without rosin. These compounds are typical in plant essential oils and rosins [38] and presumably indicate that very slight remaining rosin could have been transferred within the preparation (spinning or sample collection) of rosin-containing and 'pure' fibres.

The fibres with Ag-doping resulted in rather high total emissions (TVOCs) at $105{ }^{\circ} \mathrm{C}$. The chemical content was not ambiguous and reflected the typical PLA chemistry-related VOC release. In addition, a significant release of 2-pyrrolidinone was found contrary to pure PLA emissions. The 2-pyrrolidinone release stem from the poly(vinylpyrrolidone) surface treatment applied to the Ag particles [9]. It should be noted that PLA softens already at $55^{\circ} \mathrm{C}[39]$, thus, the tested PLA polyfilaments have presumably begun to degrade at $105^{\circ} \mathrm{C}$.

\subsection{Long-Term Performance of Polyfilament Fibres}

The effect of UV exposure as a function of UV exposure time is presented in Figure 3a-c. It can be seen that the effect of UV ageing was essentially unaffected by the addition of rosin. For pure PE fibres as well as for the PE-rosin $(10 \mathrm{w}-\%)$ fibres, most of the degradation occurred during the very first week of the irradiation period. This result is supported by the high values of strength (Table 5) for the rosin-modified fibres compared to the pure PE fibres. Rosin has been reported to be well integrated and dispersed to the polyethylene bulk in melt-spun fibres [6].

For the PLA fibres with and without rosin, the ageing trend was similar to PE fibres although the rosin-modified fibres were subject to a significant (absolute) impact and the ultimate strength was in practice lost during a total of two-week UV exposure. The previous work indicated lower quasi-static performance of rosin in PLA polyfilaments [6] compared to PE (and PA as well as polypropylene fibres). However, the low as-spun strength of the 0exposure fibres (fPLA10 series), shown in Table 5, should be noted when comparing the pure and rosin-modified fibres in Figure 3. In addition, PLA degrades during the subsequent melting and processing cycles of rosin mixing. Moreover, rosin (its functional groups and terpenes) might have reacted with part of the migrants, i.e., lactic acid, lactoyllactic acid, even lactide. For this, the rosin-containing PLA fibres are not exactly comparable to the pure PLA fibres.

The results of the degradation of PE fibres, with and without rosin, due to standard washing suggest that rosin actually might have an observable negative effect on the washing durability. Noting that the initial, reference (0 washings) strength is $3.6 \%$ lower for the fPE10-160 series with rosin compared to pure PE fibres, the $24 \%$ increase in the degradation after ten washing cycles indicates a notable washing-related influence by rosin. This is expected because the melting and degradation of rosin itself begins at $\approx 70{ }^{\circ} \mathrm{C}$ [6]. For the melt-spun fibres with any local low-quality integration (i.e., clustering), the high temperature presumably leads to merging and diffusion of rosin inside the PE bulk. Contrary to all of the PE fibres, PLA fibres simply re-deform at $70{ }^{\circ} \mathrm{C}$ due to the low glass transition temperature $\left(\mathrm{T}_{g}=55^{\circ} \mathrm{C}\right.$ [39]) and hydrolysis at temperatures of $45-60{ }^{\circ} \mathrm{C}$ in hydro-thermal conditions [16]. After the temperature reaches the washing temperature of $70^{\circ} \mathrm{C}$ in PLA, the filaments have already deformed and do not represent fibres and cannot be tested as filaments. 


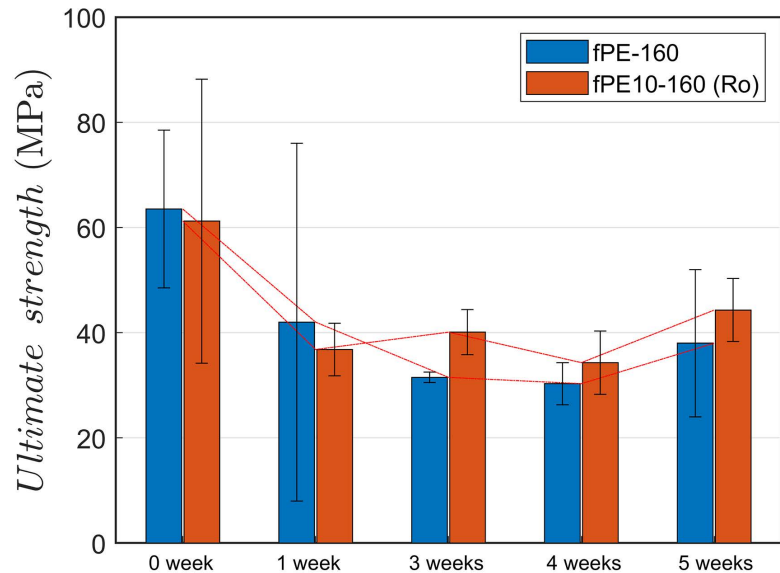

(a)

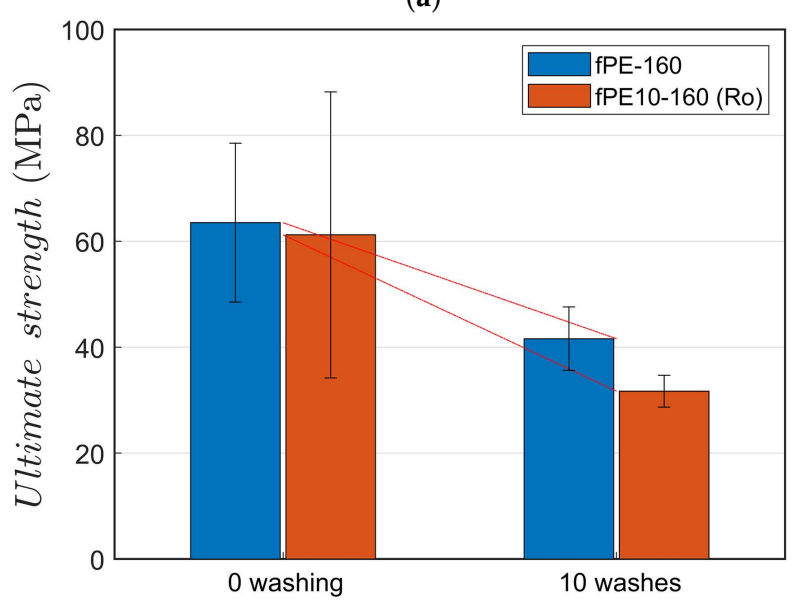

(c)

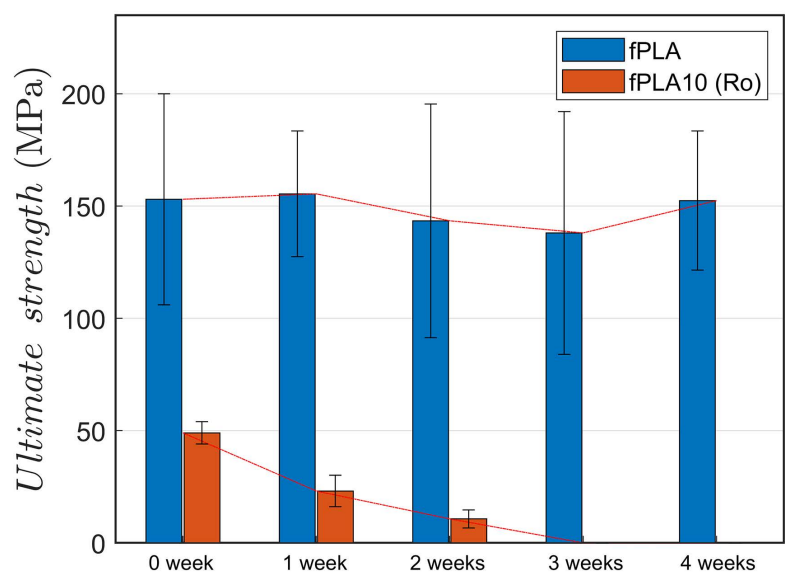

(b)

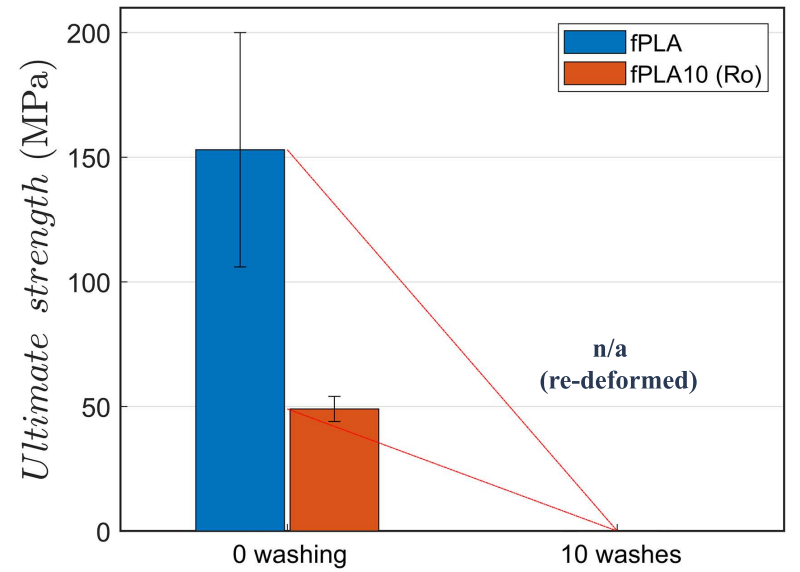

(d)

Figure 3. The effect of UV exposure on the ultimate strength of: (a) PE fibres with and without rosin; (b) PLA fibres with and without rosin. The effect of standard washing $\left(70^{\circ} \mathrm{C}\right)$ on the ultimate strength of: (c) PE fibres with and without rosin; (d) PLA fibres with and without rosin.

The results about the degradation related to UV radiation and washing revealed significant degradation of fibres in realistic application-simulating environments. For better understanding and development of the fibre chemistry, it is important to know how great is the pure thermal ageing - without the effects of UV and moisture. Figure 4 shows the results of thermal ageing at $60^{\circ} \mathrm{C}$. The effects of the long-term elevated temperature on the PE fibres with and without rosin are interesting - the effects are dependent on the melt-spinning temperature (sensor of the spinneret unit). The effect of the processing temperature on fibre strength (tenacity) has been reported earlier [6] and is evident from the as-spun strength values in Table 5. It is important to note that the degrading effect of long-term elevated temperature and the observed dependence on the spinning temperature were not observed to be dependent on the addition of rosin. This means that the degradation of rosin does not begin when the temperature is below $70^{\circ} \mathrm{C}$-even when the conditioning is continued for several weeks. The PLA fibres naturally lost their fibrous form at $60^{\circ} \mathrm{C}$ during the very first measuring interval (seven days) and could not be tested. 


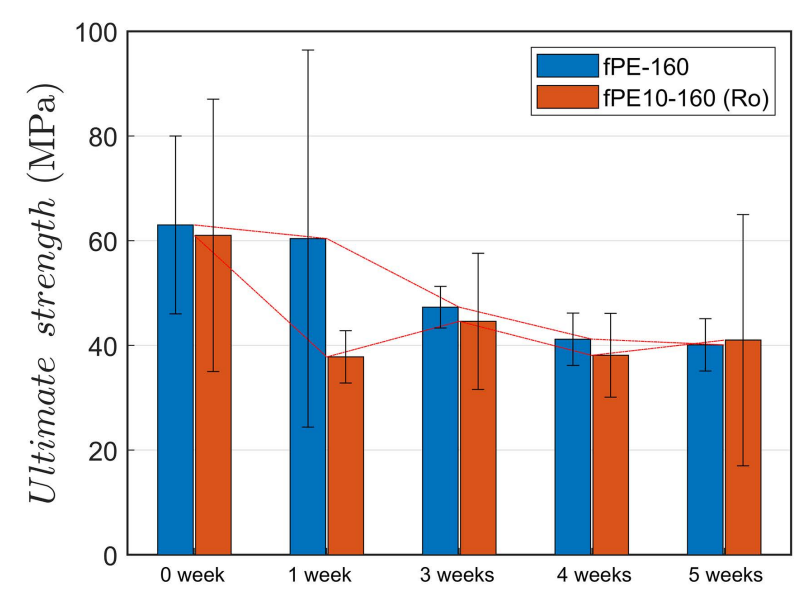

(a)

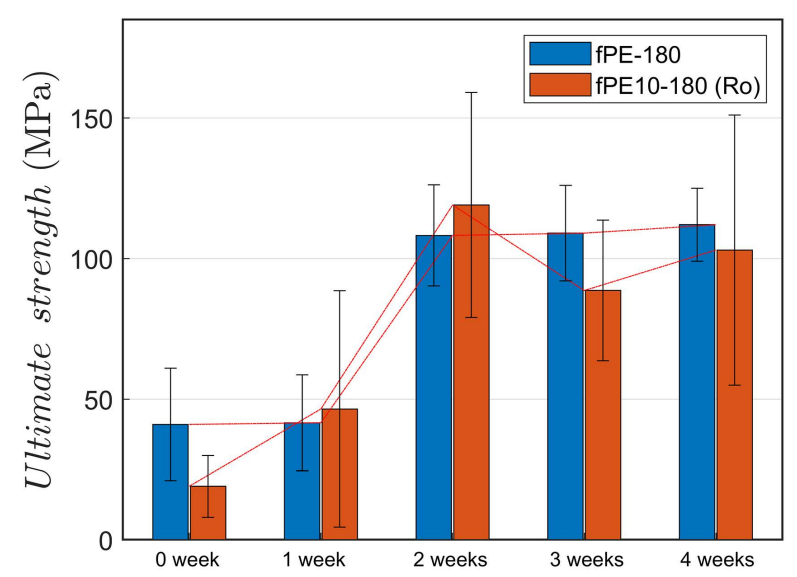

(b)

Figure 4. The effects of thermal ageing at $60^{\circ} \mathrm{C}$ : (a) PE fibres (with melt-spinning temperature of $160{ }^{\circ} \mathrm{C}$ ) with and without rosin; (b) PE fibres (with melt-spinning temperature of $180^{\circ} \mathrm{C}$ ) with and without rosin. The PLA series fibres lost their fibrous form and could not be tested.

Along with mechanical performance, the antibacterial response should remain in the polyfilaments during anticipated operation. The durability of the antibacterial response against $S$. aureus by rosin in cellulose acetate nanofibre networks is reported in the current literature-for as long as a two-month storage period at room temperature [34]. In this research, it was confirmed that the response against $S$. aureus remained after the thermal ageing period of PE-rosin polyfilaments (four weeks at $60{ }^{\circ} \mathrm{C}$ ). As shown in Figure 5, the bacterial content (S. aureus) in the medium with fibres (fPE10-180 series) decreased from $10^{5} \mathrm{cfu} / \mathrm{mL}$ in $24 \mathrm{~h}$ to below the detection limit $\left(3 \times 10^{1} \mathrm{cfu} / \mathrm{mL}\right)$.

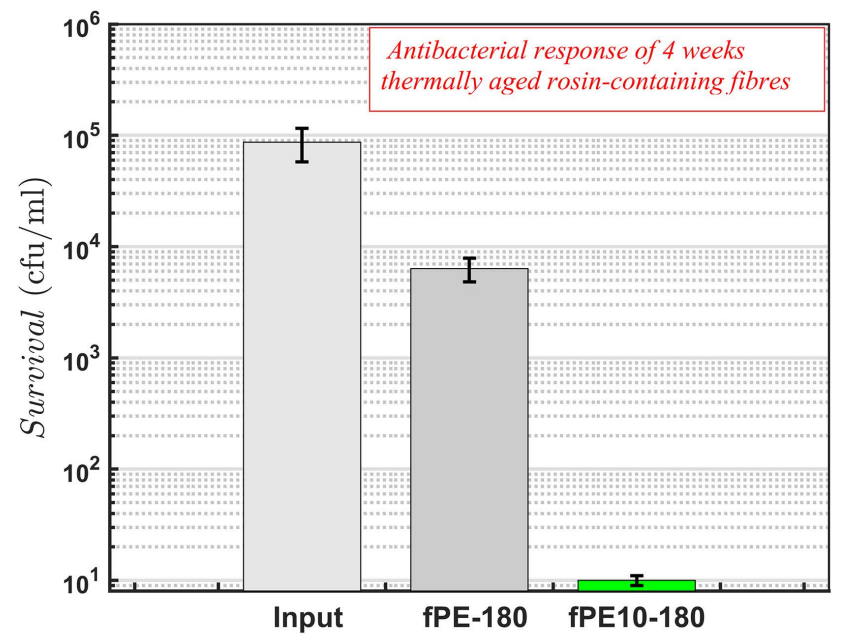

Figure 5. Antibacterial response of melt-spun polyfilaments against $S$. aureus in liquid (Ringer's solution, 1/4 strength) after $24 \mathrm{~h}$ mixing at room temperature: four weeks thermally aged $\left(60{ }^{\circ} \mathrm{C}\right) \mathrm{PE}$ polyfilament fibres with and without rosin. PLA fibres lose their fibrous form at $60{ }^{\circ} \mathrm{C}$ and can not be tested as polyfilament fibres. The detection limit is $3 \times 10^{1} \mathrm{cfu} / \mathrm{mL}$.

\section{Discussion}

The results of mechanical testing for the fibre durability showed that PE fibres with and without rosin are durable and strong even when relatively large rosin concentration (10 w- $\%)$ is used during the polymer blending. The significant effect of the spinning temperature on the long-term thermal ageing $\left(60^{\circ} \mathrm{C}\right)$ emphasized the essence of processing-related parameters and induced phenomena, such as crystallinity [40,41] and for some events cross-linking [42], when using natural components, like rosin. The processing parameters 
are typically adjusted per specific application and design criteria of the polyfilament. However, in this study, the strength deterioration or development was not found observably dependent on the addition of rosin. The change in the measured ultimate strength in time was similar by its trend for pure and the rosin-modified fibres. The reported thermal gravimetric data [6] for the exact rosin and the VOC analysis of this study suggest that some amount of rosin (components) is emitted or degraded from the polymer system for temperatures above $60^{\circ} \mathrm{C}$. Based on the VOC data, terpene and acid functional groups in general - that are typically reported to be responsible for the antibacterial response-are at least partly removed. The removal of these compounds did not finally affect the antibacterial response (at the analysed bacterial input level and mixing time of $24 \mathrm{~h}$ ), even after four weeks of thermal ageing at $60^{\circ} \mathrm{C}$. Therefore, it is suggested that the relatively high rosin content applied to the polyfilaments in this study let the antibacterial response to remain despite the immediate changes (by emissions).

The melt-spinning of PLA fibres with natural antibacterial response and with adequate mechanical durability as the main targets was noticed challenging in this study. The results about the poor performance at $60^{\circ} \mathrm{C}$ (lost integrity) are strongly supported by the current literature [43]. For a cellulose-based filler, Aouat et al. reported that it was not possible to even determine Young's modulus after nine days of conditioning at $60^{\circ} \mathrm{C}$ independent of the dosage of natural additives (cellulose) [16]. In summary, when noting the results of antibacterial response of the fibres modified by the selected Ag-containing additive, the selected PLA (grade) is less preferred polymer basis for polyfilament melt-spinning with rosin compared to the developed PE compounds with rosin.

\section{Conclusions}

The long-term durability and ageing due to the anticipated environment of application (i.e., textiles, industrial filters) of polyfilaments were studied for PE and PLA melt-spun polyfilaments with pine gum rosin as natural antibacterial additive. The analysis of weathering in this study included a UV irradiation period of 4-5 weeks, standard washing at $70{ }^{\circ} \mathrm{C}$, and thermal ageing at $60{ }^{\circ} \mathrm{C}$ for four weeks. The release of volatile organic compounds was studied using the standard VOC analysis at temperatures of $25^{\circ} \mathrm{C}, 60^{\circ} \mathrm{C}$ and $105^{\circ} \mathrm{C}$. The antibacterial response against Gram-positive S. aureus, as reported earlier for several rosin-containing polymer fibres, was compared with fibres modified by rival synthetic Ag-containing additive here. In the end, the antibacterial response of the mechanically durable PE fibres with and without rosin was confirmed-after four weeks of thermal ageing. The results revealed the following outcomes:

- A high $20 \mathrm{w}-\%$ of rosin content was be applied for melt-spun PE and PLA polyfilaments by using a copolymer-type surfactant (F-127, Pluronic) but the ultimate mechanical properties at ambient conditions were not improved;

- The total VOC emissions from the melt-spun PE fibres were lower for those fibres that were modified with $10 \mathrm{w}-\%$ of rosin and when analysed over a temperature range of 25...6 $60^{\circ} \mathrm{C}$;

- PE fibres with a $10 \mathrm{w}-\%$ of rosin were mechanically durable against UV-radiation, thermal ageing at $60^{\circ} \mathrm{C}$ and standard washing cycles at $70{ }^{\circ} \mathrm{C}$ as well as in terms of a strong antibacterial response against $S$. aureus.

Supplementary Materials: The following are available online. Additional data available named Supplementary Material 1 (DOI: 10.5281/zenodo.4310995) (https: / doi.org/10.5281/zenodo.4275721) and Supplementary Material 2 (DOI: 10.5281/zenodo.4275721) (https:/ /doi.org/10.5281/zenodo.43 10995).

Author Contributions: Conceptualization, M.K., R.L. and P.S.; methodology, A.P., T.M.T., R.L. and P.P.; formal analysis, J.M.-A. and M.H.; investigation, J.M.-A., M.K., S.P. and A.P.; resources, V.Y.; data curation, M.K.; writing-original draft preparation, M.K.; writing-review and editing, all; visualization, M.K.; project administration, M.K. and P.S. All authors have read and agreed to the published version of the manuscript. 
Funding: This investigation was funded by a grant from the Business Finland and participating industry (PIHKA, 1763/31/2016).

Data Availability Statement: Data available by request until 2023.

Acknowledgments: M.K. and A.P. acknowledge researchers Tommi Lehtinen and Teija Joki for laboratory work (Tampere University, Finland) during spinning and fibre testing.

Conflicts of Interest: The authors declare no conflict of interest.

Sample Availability: Samples may be available by request.

\section{References}

1. Sandin, G.; Peters, G. Environmental impact of textile reuse and recycling-A review. J. Clean. Prod. 2018, 184, 353-365. [CrossRef]

2. Leskinen, P.; Cardellini, G.; Gonzales-Garcia, S.; Hurmekoski, E.; Sathre, R.; Seppälä, J.; Smyth, C.; Stern, T.; Verkerk, P. Substitution Effects of Wood-Based Products in Climate Change Mitigation; Technical Report Science to Policy 7; European Forest Institute (EFI): Joensuu, Finland, 2018.

3. Jabbar, A.; Tausif, M.; Tahir, H.; Basit, A.; Bhatti, M.; Abbas, G. Polylactic acid/lyocell fibre as an eco-friendly alternative to polyethylene terephthalate/cotton fibre blended yarns and knitted fabrics. J. Text. Inst. 2020, 111, 129-138. [CrossRef]

4. Zheng, X.; Ding, X.; Guan, J.; Gu, Y.; Su, Z.; Zhao, Y.; Tu, Y.; Li, X.; Li, Y.; Li, J. Ionic liquid-grafted polyamide 6 by radiation-induced grafting: New strategy to prepare covalently bonded ion-containing polymers and their application as functional fibers. ACS Appl. Mater. Interfaces 2019, 11, 5462-5475. [CrossRef]

5. Haaparanta, A.M.; Järvinen, E.; Cengiz, I.; Ellä, V.; Kokkonen, H.; Kiviranta, I.; Kellomäki, M. Preparation and characterization of collagen/PLA, chitosan/PLA, and collagen/chitosan/PLA hybrid scaffolds for cartilage tissue engineering. J. Mater. Sci. Mater. Med. 2014, 25, 1129-1136. [CrossRef] [PubMed]

6. Kanerva, M.; Puolakka, A.; Takala, T.; Elert, A.; Mylläri, V.; Jönkkäri, I.; Sarlin, E.; Seitsonen, J.; Ruokolainen, J.; Saris, P.; et al. Antibacterial polymer fibres by rosin compounding and melt-spinning. Mater. Today Commun. 2019, 20, 100527. [CrossRef]

7. Son, W.; Youk, J.; Park, W. Antimicrobial cellulose acetate nanofibers containing silver nanoparticles. Carbohydr. Polym 2006, 65, 430-434. [CrossRef]

8. Rangari, V.; Mohammad, G.; Jeelani, S.; Hundley, A.; Vig, K.; Singh, S.; Pillai, S. Synthesis of Ag/CNT hybrid nanoparticles and fabrication of their Nylon-6 polymer nanocomposite fibers for antimicrobial applications. Nanotechnology 2010, $21,095102$. [CrossRef]

9. Dobrovol'Skaya, I.; Yudin, V.; Drozdova, N.; Smirnova, V.; Gofman, I.; Popova, E.; Bochek, A.; Zabivalova, N.; Plugar', I.; Panarin, E. Structure and characteristics of film composites based on methyl cellulose, poviargol, and montmorillonite. Polym. Sci. Ser. A 2011, 53, 166-171. [CrossRef]

10. Hwang, S.; Jeong, S. Electrospun nano composites of poly(vinyl pyrrolidone)/nano-silver for antibacterial materials. J. Nanosci. Nanotechnol. 2011, 11, 610-613. [CrossRef]

11. Metreveli, G.; David, J.; Schneider, R.; Kurtz, S.; Schaumann, G. Morphology, structure, and composition of sulfidized silver nanoparticles and their aggregation dynamics in river water. Sci. Total Environ. 2020, 739, 139989. [CrossRef]

12. Yaqoob, A.; Umar, K.; Ibrahim, M. Silver nanoparticles: Various methods of synthesis, size affecting factors and their potential applications-A review. Appl. Nanosci. 2020, 10, 1369-1378. [CrossRef]

13. Meireles Gouvâ, D.; Santos Mendonça, R.; Lopez Soto, M.; Souza Cruz, R. Acetate cellulose film with bacteriophages for potential antimicrobial use in food packaging. LWT Food Sci. Technol. 2015, 63, 85-91. [CrossRef]

14. Han, D.; Sherman, S.; Filocamo, S.; Steckl, A. Long-term antimicrobial effect of nisin released from electrospun triaxial fiber membranes. Acta Biomater. 2017, 53, 242-249. [CrossRef] [PubMed]

15. Gankov, N. Effect of aging of polycaproamide crumb on the quality of vidlon textile fibre. Fibre Chem. 2004, 36, 119-121. [CrossRef]

16. Aouat, T.; Kaci, M.; Lopez-Cuesta, J.; Devaux, E. Investigation on the durability of PLA bionanocomposite fibers under hygrothermal conditions. Front. Mater. 2019, 6, 323. [CrossRef]

17. Söderberg, T.; Gref, R.; Holm, S.; Elmros, T.; Hallmans, G. Antibacterial activity of rosin and resin acids in vitro. Scand. J. Plast. Reconstr. Surg. Hand Surg. 1990, 24, 199-205. [CrossRef] [PubMed]

18. Nirmala, R.; Woo-il, B.; Navamathavan, R.; Kalpana, D.; Lee, Y.S.; Kim, H.Y. Influence of antimicrobial additives on the formation of rosin nanofibers via electrospinning. Colloids Surf. B Biointerfaces 2013, 104, 262-267. [CrossRef]

19. Sjöström, E. Wood Chemistry-Fundamentals and Applications; Academic Press: Cambridge, MA, USA, 1993; ISBN 978-0-08-092589-9.

20. Himejima, M.; Hobson, K.; Otsuka, T.; Wood, D.; Kubo, I. Antimicrobial terpenes from oleoresin of ponderosa pine tree Pinus ponderosa: A defense mechanism against microbial invasion. J. Chem. Ecol. 1992, 18, 1809-1818. [CrossRef]

21. Ekeberg, D.; Flate, P.O.; Eikenes, M.; Fongen, M.; Naess-Andresen, C.F. Qualitative and quantitative determination of extractives in heartwood of Scots pine (Pinus sylvestris L.) by gas chromatography. J. Chromatogr. A 2006, 1109, 267-272. [CrossRef]

22. Vainio-Kaila, T.; Hänninen, T.; Kyyhkynen, A. Effect of volatile organic compounds from Pinus sylvestris and Picea abies on Staphylococcus aureus, Escherichia coli, Streptococcus pneumoniae and Salmonella enterica serovar Typhimurium. Holzforschung 2017, 71, 905-912. [CrossRef] 
23. Vainio-Kaila, T.; Zhang, X.; Hänninen, T.; Kyyhkynen, A.; Johansson, L.S.; Willför, S.; Österberg, M.; Siitonen, A.; Rautkari, L. Antibacterial effects of wood structural components and extractives from Pinus sylvestris and Picea abies on Methicillin-resistant Staphylococcus aureus and Escherichia coli O157:H7. Bioresources 2017, 12, 7601-7614.

24. Vainio-Kaila, T.; Kyyhkynen, A.; Rautkari, L.; Siitonen, A. Antibacterial effects of extracts of pinus sylvestris and picea abies against Staphylococcus aureus, Enterococcus faecalis, Escherichia coli, and Streptococcus pneumoniae. BioResources 2015, 10, 7763-7771. [CrossRef]

25. Shi, Y.; Si, H.; Wang, P.; Chen, S.; Shang, S.; Song, Z.; Wang, Z.; Liao, S. Derivatization of natural compound $\beta$-pinene enhances its in vitro antifungal activity against plant pathogens. Molecules 2019, 24, 3144. [CrossRef]

26. Rosu, L.; Mustafa, F.; Rosu, D.; Varganici, C.; Rosca, I.; Rusu, T. Bio-based coatings from epoxy resins crosslinked with a rosin acid derivative for wood thermal and anti-fungal protection. Prog. Org. Coat. 2020, 151, 106008. [CrossRef]

27. Cheng, C.; Zhou, F.; Lu, M.; Sun, J. Inducible pine rosin defense mediates interactions between an invasive insect-fungal complex and newly acquired sympatric fungal associates. Integr. Zool. 2015, 10, 453-464. [CrossRef] [PubMed]

28. Ghimire, R.; Markkanen, J.; Kivimäenpää, M.; Lyytikäinen-Saarenmaa, P.; Holopainen, J. Needle removal by pine sawfly larvae increases branch-level VOC emissions and reduces below-ground emissions of scots pine. Environ. Sci. Technol. 2013, 47, 4325-4332. [CrossRef] [PubMed]

29. Sipponen, A.; Peltola, R.; Jokinen, J.J.; Laitinen, K.; Lohi, J.; Rautio, M.; Männistö, M.; Sipponen, P.; Lounatmaa, K. Effects of Norway spruce (Picea abies) resin on cell wall and cell membrane of Staphylococcus aureus. Ultrastruct. Pathol. 2009, 33, 128-135. [CrossRef] [PubMed]

30. Tikka, P.; Gullichsen, J. Chemical Pulping Part 2. Chapter Recovery of Chemicals and Energy; Papermaking Science and Technology: Espoo, Finland. 2000; pp. B378-B388, ISBN 952-5216-06-3.

31. Vaisman, L.; Wagner, H.D.; Marom, G. The role of surfactants in dispersion of carbon nanotubes. Adv. Colloid Interface Sci. 2006, 128-130, 37-46. [CrossRef]

32. ISO. Sample Preparation-Dispersing Procedures for Powders in Liquids; Standard No.14887(E); International Organization for Standardization (ISO): Geneva, Switzerland, 2000.

33. Siljander, S.; Keinänen, P.; Räty, A.; Ramakrishnan, K.; Tuukkanen, S.; Kunnari, V.; Harlin, A.; Vuorinen, J.; Kanerva, M. Effect of Surfactant Type and Sonication Energy on the Electrical Conductivity Properties of Nanocellulose-CNT Nanocomposite Films. Int. J. Mol. Sci. 2018, 19, 1819. [CrossRef]

34. Kanerva, M.; Matrenichev, V.; Layek, R.; Takala, T.; Laurikainen, P.; Sarlin, E.; Elert, A.; Yudin, V.; Seitsonen, J.; Ruokolainen, J.; et al. Comparison of rosin and propolis antimicrobials in cellulose acetate fibers against Staphylococcus aureus. BioResources 2020, 15, 3756-3773.

35. Piwowarek, K.; Lipińska, E.; Hać-Szymaćczuk, E.; Kieliszek, M.; Ścibisz, I. Propionibacterium spp.-source of propionic acid, vitamin B12, and other metabolites important for the industry. Appl. Microbiol. Biotechnol. 2018, 102, 515-538. [CrossRef]

36. Pickett, O.; Peterson, J. Terpenes and terpene alcohols: I vapor pressure temperature relationships. Ind. Eng. Chem. 1929, 21, 325-326. [CrossRef]

37. Sarria, S.; Wong, B.; Martín, H.; Keasling, J.; Peralta-Yahya, P. Microbial synthesis of pinene. ACS Synth. Biol. $2014,3,466-475$. [CrossRef]

38. Zhou, J.H.; Zhou, C.S.; Jiang, X.Y.; Xie, L.W. Extraction of essential oil from shaddock peel and analysis of its components by gas chromatography-mass spectrometry. J. Cent. South Univ. Technol. 2006, 13, 44-48. [CrossRef]

39. Baiju, J.; Motokucho, S.; Kojio, K.; Furukawa, M. Polyamide 6 fibers with superior mechanical properties: TPU coating techniques. J. Soc. Fiber Sci. Technol. 2009, 65, 236-240. [CrossRef]

40. Dees, J.R.; Spruiell, J.E. Structure development during melt spinning of linear polyethylene fibers. J. Appl. Polym. Sci. 1974, 18, 1053-1078. [CrossRef]

41. Wu, W.; Black, W.B. High-strength polyethylene. Polym. Eng. Sci. 1979, 19, 1163-1169. [CrossRef]

42. Jönkkäri, I.; Poliakova, V.; Mylläri, V.; Anderson, R.; Andersson, M.; Vuorinen, J. Compounding and characterization of recycled multilayer plastic films. J. Appl. Polym. Sci. 2020, 137, 49101. [CrossRef]

43. Yuan, X.; Mak, A.F.T.; Yao, K. In vitro degradation of poly(L- lactic acid) fibers in phosphate buffered saline. J. Appl. Polym. Sci. 2002, 85, 936-943. [CrossRef] 